\title{
Preservation of Fertility Potential for Gender and Sex Diverse Individuals
}

\author{
Emilie K. Johnson ${ }^{1-3, *}$ and Courtney Finlayson ${ }^{4,5}$
}

\begin{abstract}
Gender and sex diverse individuals — transgender individuals and those with disorders of sex development (DSD)_ both face medical treatments that may impair biological fertility potential. Young DSD patients also often have abnormal gonadal development. Fertility preservation for these populations has historically been poorly understood and rarely addressed. Future fertility should be discussed with gender and sex diverse individuals, particularly given recent advances in fertility preservation technologies and evolving views of fertility potential. Key ethical issues include parental proxy decision-making and uncertainty regarding prepubertal fertility preservation technologies. Many opportunities exist for advancing fertility-related care and research for transgender and DSD patients.
\end{abstract}

Key words: disorders of sex development; fertility preservation; gender dysphoria; transgender

\section{Introduction}

The term "gender and sex diversity" refers to (1) transgender individuals for whom gender identity is incongruent with birth-assigned sex and (2) individuals with differences (disorders) of sex development (DSD), also known as intersex, for whom development of chromosomal, gonadal, or anatomic sex is atypical. ${ }^{1}$ In the Lurie Children's Gender and Sex Development Program, we have found that care for one group can inform the other and patients benefit from specialists who are familiar with both. Although many distinctions exist between transgender individuals and individuals with DSD, an important area of commonality lies in the area of fertility-the ability to have a biological child.

Many medical and surgical therapies available to transgender adolescents/young adults (AYA), and children and AYA with DSD, can affect future fertility. Individuals with DSD frequently also have subfertility related to their medical condition. Gender and sex diverse individuals often choose to build a family through options such as adoption or surrogacy. For some, however, it may also be important to have the option of a biological child. Fertility preservation technologies (methods of storing eggs, sperm, or precursor reproductive tissue for future use) and societal attitudes toward "nontraditional" family structures have expanded significantly in recent years such that having a biological child is now possible for many transgender adults and adults with DSD.

The purpose of this perspectives article is to provide an introduction and overview of preservation of biological fertility potential for gender and sex diverse individuals. We also propose next steps for advancing this new clinical and research focus.

\section{Fertility Preservation for Transgender Patients}

Loss of biological fertility was once thought to be a given consequence of gender transition. ${ }^{2}$ Transgender individuals and their healthcare teams have now begun to recognize that options for preserving reproductive potential exist. A majority of transgender adults believe that fertility preservation should be discussed with and offered to them. ${ }^{3,4}$ The Endocrine Society Guidelines recommend 
counseling for transgender individuals regarding fertility before initiating gender-affirming hormonal therapy. ${ }^{5}$ Knowledge of the effects of medical treatments on fertility, familiarity with available fertility preservation options, and an appreciation for potential ethical issues are all necessary to effectively counsel patients.

\section{Medical treatments-effects on fertility}

Pubertal suppression with gonadotropin releasing agonists (GnRH-a) not only prevents development of potentially distressing secondary sex characteristics but also suspends germ cell maturation. Puberty appears to progress normally after discontinuation. ${ }^{6}$ However, many transgender individuals initiate gender-affirming hormone therapy concurrently with pubertal suppression, ${ }^{7}$ and thus, germ cells never fully mature. This highlights the need for discussion of fertility options before initiating $\mathrm{GnRH}-\mathrm{a}$ treatment.

Gender-affirming hormones produce impairments in gonadal histology that can cause infertility. Estrogen use by transgender women results in impaired spermatogenesis and an absence of Leydig cells in the testis. ${ }^{8,9}$ Testosterone use by transgender men causes ovarian stromal hyperplasia ${ }^{10,11}$ and follicular atresia. ${ }^{10}$ Gonadal effects of gender-affirming hormones are thought to be at least partially reversible. For example, pregnancy has been reported in transgender men who have previously used testosterone. ${ }^{12,13}$ Thresholds have not been established for the amount and duration of exogenous testosterone or estrogen exposure necessary to have a permanent negative effect on fertility.

For patients who elect surgical transition, gonadectomy will render them permanently sterile. Thus, this is the last opportunity for fertility preservation for patients who choose gender reassignment surgery that includes gonadal removal.

\section{Fertility preservation options}

Table 1 summarizes current fertility preservation techniques, stratified by pubertal status. Transgender individuals who have undergone spontaneous biological puberty consistent with their birth-assigned sex may elect for fertility preservation before initiation of gender-affirming hormone therapy. For transgender women, this involves sperm preservation, with a sample typically obtained through masturbation. When this is not possible due to anatomic, emotional, or physical maturity concerns, sperm can be retrieved directly from the testis using a surgical procedure, testicular sperm extraction (TESE). For transgender men who have undergone female puberty, fertility preservation options include hormonal stimulation followed by oocyte or embryo cryopreservation.

Ovarian tissue cryopreservation (OTC), an experimental procedure in which prepubertal ovarian tissue is harvested and preserved, is offered to women with cancer. ${ }^{14}$ OTC is a potential area of future investigation for peripubertal affirmed males, as it does not require hormonal stimulation. Similarly, testicular cryopreservation may offer fertility potential for peripubertal affirmed females. Prepubertal tissue cryopreservation protocols for oncology patients could be expanded to transgender individuals in the future. Although the technology is still developing, fertility experts expect that precursor egg and sperm cells will soon be able to be matured and used with assisted reproductive technologies to produce a biological child. ${ }^{15-17}$

\section{Ethics}

A primary ethical concern regarding fertility preservation for transgender AYA is that parents must make decisions about fertility preservation if it is to occur before initiation of pubertal suppression and/or gender-affirming hormone therapy. Although this is done with patient assent, children are often not intellectually or emotionally mature enough to predict their future desires or understand the implications of their present decisions. This results in transgenerational fertility decision-making, which may not align with future patient desires; disagreement between the patient and parent regarding fertility preservation may also arise. In addition, there may be patient distress associated with procurement processes, given that the gamete type is not congruent with gender identity. Furthermore, peripubertal tissue cryopreservation is experimental. It is unknown if and when assisted reproductive technologies will be available to mature germ cells. Thus, patients are potentially incurring surgical risk and storing gonadal tissue without the guarantee of future fertility.

Table 1. Current Fertility Preservation Options

\begin{tabular}{lll}
\hline Gamete type & Pre- or peripubertal options & \multicolumn{1}{c}{ Postpubertal options } \\
\hline $\begin{array}{l}\text { Oocyte } \\
\text { Spermatozoa }\end{array}$ & $\begin{array}{l}\text { Ovarian tissue cryopreservation } \\
\text { Testicular tissue cryopreservation }\end{array}$ & $\begin{array}{l}\text { Ovarian stimulation, with oocyte retrieval and cryopreservation of oocyte or embryo } \\
\text { Sperm banking, with sample obtained through masturbation or surgical biopsy }\end{array}$ \\
\hline
\end{tabular}

${ }^{\mathrm{a}}$ Experimental. 
Table 2. DSD Fertility Effects, Research Needs, and Fertility Preservation Techniques

\begin{tabular}{|c|c|c|c|}
\hline Characteristic & Fertility effect & Research needs & $\begin{array}{l}\text { Applicable fertility } \\
\text { preservation technique }\end{array}$ \\
\hline Abnormal gonads (streak, dysgenetic) & $\begin{array}{l}\text { Congenital and/or progressive } \\
\text { gonadal failure }\end{array}$ & $\begin{array}{l}\text { Establish presence and } \\
\text { quality of germ cells } \\
\text { by age }\end{array}$ & $\begin{array}{l}\text { Cryopreserve testicular } \\
\text { or ovarian tissue }\end{array}$ \\
\hline Risk of gonadal malignancy & $\begin{array}{l}\text { Gonadectomy traditionally } \\
\text { performed }\end{array}$ & $\begin{array}{l}\text {-Malignancy risk- } \\
\text { stratification by condition } \\
\text {-Surveillance protocols } \\
\text { if gonads retained }\end{array}$ & $\begin{array}{l}\text { If gonadectomy required } \\
\text {-Postpubertal: preserve sperm } \\
\text { or oocytes } \\
\text {-Prepubertal: cryopreserve } \\
\text { nonmalignant tissue }\end{array}$ \\
\hline Abnormal hormone production & $\begin{array}{l}\text { Abnormal sperm and } \\
\text { oocyte production }\end{array}$ & Determine fertility rates & $\begin{array}{l}\text { Existing assisted reproductive } \\
\text { techniques: ovarian } \\
\text { stimulation, testicular } \\
\text { sperm extraction }\end{array}$ \\
\hline $\begin{array}{l}\text { Discordance between gender identity } \\
\text { and germ cell type }\end{array}$ & $\begin{array}{l}\text { Reframing view allows for } \\
\text { biological fertility potential }\end{array}$ & $\begin{array}{l}\text { Patient/parent } \\
\text { perspectives needed }\end{array}$ & N/A \\
\hline
\end{tabular}

${ }^{\mathrm{a}}$ Experimental.

DSD, disorders of sex development.

\section{Fertility Preservation for Patients with DSD}

As for transgender patients, infertility or sterility has often been assumed for many DSD patients. The approach to DSD care has shifted in the last few decades from the assumption that individuals were psychosexually neutral and early sex reassignment surgery was preferred, without concern for future fertility, to one in which it is acknowledged that the formation of gender identity is poorly understood and that irreversible surgeries should be avoided or performed only with great caution and counseling. In current practice, the future fertility potential is considered and discussed, but there remain little evidence and infrequent counseling about fertility preservation.

\section{DSD conditions-fertility effects}

The term DSD refers to a diverse group of conditions that result in atypical sex development. This includes sex chromosome abnormalities, including Turner and Klinefelter syndrome, disorders of gonadal development, including complete and partial gonadal dysgenesis, and disorders of androgen synthesis or action-complete and partial androgen insensitivity (CAIS, PAIS), con- genital adrenal hyperplasia, and 5-alpha reductase deficiency. These diverse DSD conditions differ in etiology and fertility potential. DSD patients are at risk for potential infertility or sterility due to the following: (1) abnormal gonadal development, (2) gonadectomy for malignancy risk, (3) abnormal hormonal function, and (4) discordance between gonadal type and gender identity. These often overlapping etiologies are outlined in Table 2, along with description of further required advances in research to better predict fertility potential and applicable preservation techniques.

\section{Fertility preservation options}

Currently, the treatment for infertility in DSD is limited. General options for pre and postpubertal fertility preservation are the same as for transgender patients (Table 1). However, the inherent gonadal abnormalities faced by DSD patients make the possibility of fertility preservation less certain. Most reports of success in achieving biological offspring are in males, resulting from TESE and/or intracytoplasmic sperm injection; this has been reported in Klinefelter syndrome, PAIS, and 5-alpha reductase deficiency. ${ }^{18-21}$

Table 3. Comparison of Fertility-Related Issues for Individuals with Transgender Versus DSD Conditions

\begin{tabular}{|c|c|c|}
\hline & Transgender & DSD \\
\hline Inherent gonadal abnormality & No & Frequent \\
\hline Medical treatments leading to infertility & Frequent & Infrequent \\
\hline Surgical treatments leading to infertility & Generally only in adulthood & Frequent in childhood \\
\hline Parental proxy decision-making & Yes & Yes \\
\hline $\begin{array}{l}\text { Medically "unnecessary" surgery for pre- } \\
\text { or peripubertal fertility preservation }\end{array}$ & Yes & Rare \\
\hline Concern about transmission of a genetic condition & No more than the general population & Yes \\
\hline Gonadal type discordant with gender identity & Always & Sometimes \\
\hline
\end{tabular}


Ethics

Ethical concerns related to proxy decision-making, patient maturity, and the experimental nature of prepubertal cryopreservation mirror those that exist for families of transgender individuals. Unique to DSD, some families are now opting to postpone gonadectomy for fertility potential purposes, with an unclear trade-off in terms of gonadal malignancy risk. Researchers are still working to define the fertility potential of many DSD conditions, so counseling regarding the balance between surgical risk, risk of malignancy, and possibility of future fertility is occurring in context of great clinical uncertainty. Finally, many DSDs are a result of genetic mutations, which could be passed to the offspring. Thus, genetic counseling is crucial, and preimplantation genetic diagnosis will play an important role in fertility preservation for DSD patients.

\section{Conclusions}

Transgender and DSD patients are largely disparate, but the medical expertise necessary to care for both overlaps, and the potential for infertility is shared. Both groups have previously been told infertility or sterility was an eventuality. Advancing scientific techniques and broadening perspectives can change this assumption. Table 3 compares key fertility issues facing transgender and DSD patients.

Fertility preservation for individuals with gender and sex diversity is a new frontier that requires research and collaboration. Priorities include delineating the fertility desires of patients and families, gaining a comprehensive understanding of treatment effects on fertility potential, further defining the gonadal potential of the diversity of DSD conditions, and expanding possibilities for reproductive tissue preservation and maturation. We must establish research protocols, develop clinical tools to guide fertility-related care, and broaden the medical community's knowledge of current and future fertility preservation possibilities.

\section{Author Disclosure Statement}

No competing financial interests exist.

\section{References}

1. Lee PA, Houk CP, Ahmed SF, Hughes IA; International Consensus Conference on Intersex organized by the Lawson Wilkins Pediatric Endocrine Society and the European Society for Paediatric Endocrinology. Consensus statement on management of intersex disorders. International Consensus Conference on Intersex. Pediatrics. 2006;118:e488-e500.

2. Lawrence AA, Shaffer JD, Snow WR, et al. Health care needs of transgendered patients. JAMA. 1996;276:874

3. Wierckx K, Van Caenegem E, Pennings G, et al. Reproductive wish in transsexual men. Hum Reprod. 2012;27:483-487.

4. De Sutter P, Kira K, Verschoor A, Hotimsky A. The desire to have children and the preservation of fertility in transsexual women: a survey. Int J Transgend. 2003;6:3.
5. Hembree WC, Cohen-Kettenis P, Delemarre-van de Waal HA, et al. Endocrine treatment of transsexual persons: an Endocrine Society clinical practice guideline. J Clin Endocrinol Metab. 2009;94:3132-3154.

6. Hagen CP, Sorensen K, Anderson RA, Juul A. Serum levels of antimullerian hormone in early maturing girls before, during, and after suppression with GnRH agonist. Fertil Steril. 2012;98:1326-1330.

7. Hembree WC. Guidelines for pubertal suspension and gender reassignment for transgender adolescents. Child Adolesc Psychiatr Clin N Am. 2011;20:725-732.

8. Schulze $C$. Response of the human testis to long-term estrogen treatment: morphology of Sertoli cells, Leydig cells and spermatogonial stem cells. Cell Tissue Res. 1988;251:31-43.

9. Lubbert $\mathrm{H}$, Leo-Rossberg I, Hammerstein J. Effects of ethinyl estradiol on semen quality and various hormonal parameters in a eugonadal male. Fertil Steril. 1992;58:603-608.

10. Pache TD, Chadha S, Gooren LJ, et al. Ovarian morphology in long-term androgen-treated female to male transsexuals. A human model for the study of polycystic ovarian syndrome? Histopathology. 1991;19:445-452.

11. Ikeda K, Baba T, Noguchi $\mathrm{H}$, et al. Excessive androgen exposure in femaleto-male transsexual persons of reproductive age induces hyperplasia of the ovarian cortex and stroma but not polycystic ovary morphology. Hum Reprod. 2013;28:453-461.

12. Light AD, Obedin-Maliver J, Sevelius JM, Kerns JL. Transgender men who experienced pregnancy after female-to-male gender transitioning. Obstet Gynecol. 2014;124:1120-1127.

13. Ellis SA, Wojnar DM, Pettinato M. Conception, pregnancy, and birth experiences of male and gender variant gestational parents: it's how we could have a family. J Midwifery Womens Health. 2015;60:62-69.

14. Loren AW, Mangu PB, Beck LN, et al. Fertility preservation for patients with cancer: American Society of Clinical Oncology clinical practice guideline update. J Clin Oncol. 2013;31:2500-2510.

15. Estes SJ. Fertility Preservation in Children and Adolescents. Endocrinol Metab Clin North Am. 2015;44:799-820.

16. Gies I, De Schepper J, Tournaye H. Progress and prospects for fertility preservation in prepubertal boys with cancer. Curr Opin Endocrinol Diabetes Obes. 2015;22:203-208.

17. Trudgen $\mathrm{K}$, Ayensu-Coker L. Fertility preservation and reproductive health in the pediatric, adolescent, and young adult female cancer patient. Curr Opin Obstet Gynecol. 2014;26:372-380.

18. Aksglaede $L$, Juul $A$. Testicular function and fertility in men with Klinefelter syndrome: a review. Eur J Endocrinol. 2013;168:R67-R76.

19. Tordjman KM, Yaron M, Berkovitz A, et al. Fertility after high-dose testosterone and intracytoplasmic sperm injection in a patient with androgen insensitivity syndrome with a previously unreported androgen receptor mutation. Andrologia. 2014;46:703-706.

20. Matsubara K, Iwamoto H, Yoshida A, Ogata T. Semen analysis and successful paternity by intracytoplasmic sperm injection in a man with steroid 5alpha-reductase-2 deficiency. Fertil Steril. 2010;94:2770.e7-e10.

21. Kang HJ, Imperato-McGinley J, Zhu YS, et al. The first successful paternity through in vitro fertilization-intracytoplasmic sperm injection with a man homozygous for the 5alpha-reductase-2 gene mutation. Fertil Steril. 2011;95:2125 e5-e8.

Cite this article as: Johnson EK, Finlayson C (2016) Preservation of fertility potential for gender and sex diverse individuals, Transgender Health 1:1, 41-44, DOI: 10.1089/trgh.2015.0010.

$\begin{aligned} & \text { Abbreviations Used } \\ \text { AYA } & =\text { adolescents/young adults } \\ \mathrm{CAIS} & =\text { complete androgen insensitivity } \\ \mathrm{DSD} & =\text { disorders of sex development } \\ \mathrm{GnRH}-\mathrm{a} & =\text { gonadotropin releasing agonists } \\ \mathrm{OTC} & =\text { ovarian tissue cryopreservation } \\ \mathrm{PAIS} & =\text { partial androgen insensitivity } \\ \mathrm{TESE} & =\text { testicular sperm extraction }\end{aligned}$

